\title{
Maternal and Gestational Influences on Deciduous and Permanent Tooth Size
}

\author{
S. M. GARN, R. H. OSBORNE, ${ }^{*}$ L. ALVESALO** and S. L. HOROWITZ***
}

Center for Human Growth and Development, University of Michigan, Ann Arbor, Michigan 48109; *Department of Anthropology, University of Wisconsin, Madison, Wisconsin 53706; **Institute of Dentistry, University of Turku, Turku 52, Finland SF 20500; and ***Columbia University School of Dentistry, New York, New York 10032

\section{J Dent Res 59(2):142-143, February 1980}

Although there have been suggestions that prenatal factors could affect crown dimensions (Bailit and Sung, Archs Oral Biol 13:155-166, 1968; Cohen, Baum, Garn, Osario and Nagy, in: Orofacial Growth and Development, Dahlberg and Graber, eds., Mout on Publishers, The Hague, 1977, pp 119-126), limitations of sample size and investigative design restrict conclusions on the magnitude of the influences. However, using newly-acquired odontometric data on selected participants in the Collaborative Perinatal Project of the National Institute of Neurological and Communicative Disorders and Stroke (NCPP), it is now possible to show systematic effects of three maternal and six developmental conditions on mesiodistal and buccolingual dimensions of both deciduous and permanent teeth.

The basic sample consists of 870 white participants studied at the time of their seven-eightyear psychological examinations in 1972 and 1973. They were selected from six cooperating institutions from the Atlantic seaboard and the West Coast (Niswander and Gordon, The Women and Their Pregnancies, D.H.E.W., Washington, 1972). Diabetes, hypothyroidism, and hypertension were the three maternal conditions selected for exploration. Gestation length, birth weight, and birth length were among the fetal or developmental variables studied. The odontometric analyses primarily involved the permanent incisors, first molars and deciduous cheek teeth (dc through dm2). A group of clinically normal children was also included for comparison, since single-source odontometric standards for deciduous and permanent teeth did not exist at the time the project was conceived. Mean crown dimensions of the normal NCPP group proved to be virtually indistin-

Received for publication March 12, 1979.

Accepted for publication June 6, 1979.

This work was supported by contracts N01NS-2302 and NO1-NS-5-2302 from the National Institute of Neurological and Communicative Disorders and Stroke, and grants DE 03443 and DE 03601 from the National Institute of Dental Research. guishable from the mean crown dimensions of the NCPP sample as a whole and the University of Michigan Longitudinal Series (cf. Moyers, Van der Linden, Riolo and McNamara, Standards of Human Occlusal Development, Center for Human Growth, Ann Arbor, MI 1976).

As shown in the summary table, all three maternal variables are associated with systematic deviations in the crown sizes of the offspring. Maternal hypothyroidism and maternal diabetes are associated with greater than average tooth size, while maternal hypertension is associated with diminished crown dimensions. Pooling data on individual teeth and expressing them uniformly as sex-specific Z-scores for simplicity of presentation, it can be seen that this range of maternal conditions is reflected in crown-size differences of nearly $1 \mathrm{SD}$. In contrast, the six birth and gestational variables are associated with smaller systematic differences in mesiodistal and buccolingual deciduous and permanent crown dimensions. Prolonged gestation, large size at birth and high birth weight are associated with larger teeth, while short gestation, lower birth weight and length are associated with smaller teeth, but the effects are not comparable in magnitude to the maternal variables described above. Student's t-tests of the hypothyroid, diabetic and high birth-length groups against each of the low birth-length, low birth-weight and hypertensive groups showed all differences significant at $p=<0.05$ for all tooth categories except those involving the permanent teeth of the diabetic progeny, which are significant by sign test.

These data, based on 870 white participants and confirmed by similar data on black children, provide important confirmation of the effect of maternal and developmental variables on the size of the teeth, including those teeth neither calcified nor dimensionally completed at birth. This new information on the 1963-1966 cohort of participants in the NCPP program provides clear indications that crown diameters may be affected during prenatal life; it also suggests how apparent population differences in crown dimensions might be brought about by selective survival, differential perinatal mortality and changing proportions of the developmentally immature now surviving into the later years (Garn, Osborne and McCabe, $A m J$ Phys Anthrop 51, 1979). 
TABLE

EFFECT OF MATERNAL AND GESTATIONAL CONDITIONS ON CROWN SIZE

\begin{tabular}{|c|c|c|c|c|c|c|}
\hline \multirow[t]{2}{*}{ Maternal/Gestational Condition } & \multicolumn{2}{|c|}{$\mathrm{dc}^{*}$} & \multicolumn{2}{|c|}{$\begin{array}{c}\text { Most } \\
\text { available } \\
\text { teeth* }\end{array}$} & \multicolumn{2}{|c|}{$\begin{array}{c}\text { Permanent } \\
\text { teeth* }\end{array}$} \\
\hline & $\mathrm{N}$ & $\mathrm{Z}$ & $\mathrm{N}$ & Z & $\mathrm{N}$ & z \\
\hline 1. Hypothyroidism during pregnancy** & 60 & $0.34+$ & 64 & $0.37+$ & 53 & $0.33+$ \\
\hline 2. Diabetes mellitus during pregnancy** & 22 & 0.26 & 26 & 0.21 & 22 & 0.06 \\
\hline 3. High birth length $(p>80)^{* *}$ & 122 & 0.18 & 133 & 0.07 & 112 & 0.14 \\
\hline 4. High birth weight $(p>80)^{* *}$ & 145 & $0.16+$ & 157 & $0.14+$ & 135 & $0.18+$ \\
\hline 5. Long gestation $(p>80)$ & 92 & 0.01 & 98 & 0.03 & 78 & 0.11 \\
\hline 6. Short gestation $(p<20)$ & 204 & -0.01 & 234 & 0.00 & 205 & -0.07 \\
\hline 7. Low birth length $(\mathrm{p}<20)$ & 177 & $-0.25+$ & 208 & $-0.12+$ & 171 & -0.14 \\
\hline 8. Low birth weight $(\mathrm{p}<20)$ & 151 & $-0.26+$ & 178 & $-0.22+$ & 158 & $-0.24+$ \\
\hline 9. Hypertension during pregnancy & 23 & $-0.46+$ & 25 & -0.28 & 20 & -0.26 \\
\hline
\end{tabular}

* Most available tooth $(\mathrm{dc}), 3$ most available teeth $(\mathrm{dc}, \mathrm{dm} 2, \mathrm{I})$ and 3 most common permanent teeth (11, I2, M1), respectively.

+Significantly different $(\mathrm{p}<0.05)$ from the Normal group by t-test; for other differences, see text.

** Significantly different from conditions $7-9$ in crown size by t-tests.

\section{INTERNATIONAL CONFERENCE ON ORAL SURGERY 23-26 JUNE 1980 TRINITY COLLEGE, DUBLIN}

SYMPOSIUM A. FACIAL PAIN

CHAIRMAN: PROF. D. POSWILLO

SYMPOSIUM B. OSTEOMYELITIS OF THE JAWS

CHAIRMAN: MR. N. ROWE

WITH PANELS OF INTERNATIONAL REPUTE

DEADLINE FOR RECEIPT OF ABSTRACTS OF SCIENTIFIC PAPERS AND FILMS 18 JANUARY 1980.

THE SECRETARIAT, VII I.A.O.S. CONFERENCE, 12 PEMBROKE PARK, DUBLIN 4, IRELAND. 